\title{
Ventilatory responses to exercise in adults after repair of tetralogy of Fallot
}

\author{
Andrew L Clark, Michael A Gatzoulis, Andrew N Redington
}

\begin{abstract}
Background-Adult patients with total correction of tetralogy of Fallot may have poor exercise capacity associated with impaired right heart function and in particular pulmonary regurgitation. The ventilatory responses to exercise were studied in a group of such patients to assess relations between ventilation, exercise capacity, and right ventricular function.

Methods-30 patients (7 female) (aged $27.8(6 \cdot 0)$ years) and 30 (7 female) controls of a similar age range were studied prospectively. All underwent exercise testing with metabolic gas exchange to determine peak oxygen consumption (peak $\dot{V} \mathrm{O}_{2}$ ), and (as indices of the ventilatory response) the slope of the relation between both respiratory rate $(R R)$ and ventilation ( $\left.\dot{V}_{E}\right)$ against carbon dioxide production $\left(\mathrm{VCO}_{2}\right)$. Patients were studied with pulsed wave Doppler echocardiography to determine pulmonary arterial systolic and diastolic flow characteristics. Patients were defined as having restrictive right ventricular function where diastolic pulmonary forward flow was seen coincident with atrial systole.
\end{abstract}

Results-In the group with tetralogy of Fallot mean (SD) peak $\dot{V} o_{2}$ was $35 \cdot 3(7 \cdot 5)$ $\mathrm{ml} / \mathrm{kg} / \mathrm{min}(93.6(15.3) \%$ of expected for age, weight, height and sex). The RR/ن்O slope was steeper in the Fallot group (6.8 (2.6) $v 9.6(4.7), P<0.02)$. Those with restrictive right ventricles achieved a higher peak $\mathrm{Vo}_{2}$ than those without $(82.5$ $(10.1) \% v 100.9(13.8), P<0.001)$. In the Fallot group alone, there was an inverse relation between ventilatory response and peak $\dot{V}_{2}\left(R R / \dot{V} \mathrm{CO}_{2} v\right.$ peak $\dot{\mathrm{Vo}}_{2} ; r=$ - 0.63, $\mathrm{P}=0.003: \dot{\mathrm{V}}_{\mathrm{E}} / \dot{\mathrm{V}}_{\mathrm{CO}} v$ peak $\dot{\mathrm{Vo}}_{2} ; r=$ $-0.62, P<0.001$ ).

Conclusions-Many of these patients with repaired tetralogy of Fallot had near normal exercise capacity, but as exercise capacity decreased, the ventilatory response to exercise increased. This was not due to alterations in pulmonary function tests or to the effects of cardiac size causing decreased lung volume. It may be that the increased ventilatory rate at a given level of carbon dioxide production acts as a respiratory pump aiding right ventricular function.

(Br Heart f 1995;73:445-449)
Keywords: tetralogy of Fallot; exercise capacity; ventilatory response

Biventricular repair has become the standard surgical treatment for tetralogy of Fallot. ${ }^{1}$ When this approach is used left ventricular function seems to be well preserved ${ }^{2}$ but right ventricular function may deteriorate after repair. ${ }^{3}$ In particular, the development of pulmonary regurgitation is a poor prognostic feature associated with reduced exercise capacity. ${ }^{45}$

We have recently described abnormalities of right ventricular diastolic function after surgical correction for tetralogy of Fallot. In some patients forward flow in the pulmonary artery during diastole suggested that the right ventricle may behave as a passive conduit allowing forward flow to the pulmonary artery during atrial systole. ${ }^{6}$ Although the presence of this restrictive physiology predicts slow postoperative recovery, the presence of a restrictive right ventricle may limit the deleterious effects of pulmonary regurgitation. ${ }^{67}$

In conditions where exercise is limited by cardiac abnormality, such as chronic heart failure $^{89}$ and in patients surviving long term after Fontan's procedure for congenital heart disease, ${ }^{10}$ there is an inverse relation between exercise capacity and ventilatory response to exercise. We were interested to determine the ventilatory responses in patients with repaired tetralogy of Fallot. We speculated that for patients with repair of tetralogy of Fallot, the relation between ventilation and exercise performance might be present because in such patients the respiratory cycle could act as an accessory pump that helps to increase blood flow through the right heart, particularly where the right heart is limited by pulmonary regurgitation or right ventricular impairment.

\section{Patients and methods}

Thirty (seven female) patients with a diagnosis of tetralogy of Fallot were assessed prospectively. They were recruited from a group of 80 patients operated on by one surgeon between 1958 and 1979. Of these, 33 had been lost to follow up and 17 declined to take part in the exercise testing. All had had definitive surgical repair at the age of $6 \cdot 0(5 \cdot 5)$ years. One patient had had a transannular patch and six an infundibular patch. In the remainder of the patients, no patch was used. At the time of the assessment, the patients were (mean (SD)) $27 \cdot 8(6 \cdot 0)$ years old $(21 \cdot 8$ $(5 \cdot 8)$ years after surgery. Three had had two 


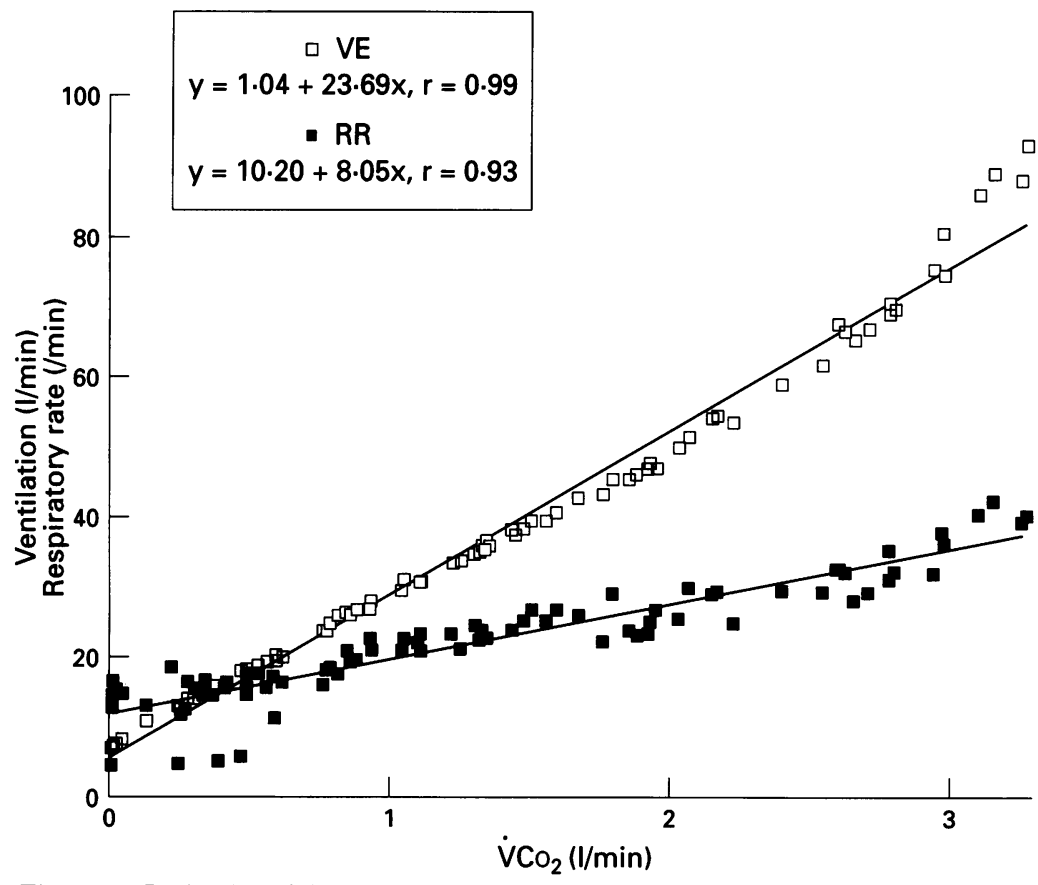

Figure 1 Derivation of the indices of ventilatory response to exercise in a patient after repair of tetralogy of Fallot. VE is ventilation, $\mathrm{VCO}_{2}$ is carbon dioxide production, and $\mathrm{RR}$ is respiratory rate. calculated as the mean of the last five breaths from the capnograph. The slopes of the relations between ventilation and carbon dioxide production $\left(\dot{\mathrm{V}} \mathrm{E} / \mathrm{VCO}_{2}\right.$ slope) and between respiratory rate and carbon dioxide production ( $\mathrm{RR} / \mathrm{VCO}_{2}$ slope) were calculated as indices of the ventilatory response to exercise (fig 1). Peak ventilation was measured, as was the end tidal carbon dioxide fraction. Exercise capacity was expressed as peak $\mathrm{Vo}_{2}$. End tidal carbon dioxide was used to estimate arterial partial pressure:

$\mathrm{Pa}\left(\mathrm{CO}_{2}\right)=\left(\mathrm{F}_{\mathrm{ET}}\left(\mathrm{CO}_{2}\right) / 100 \times\left(\mathrm{P}_{\mathrm{b}}-47\right) / 7 \cdot 5\right)$

where $\mathrm{Pa}\left(\mathrm{CO}_{2}\right)$ is the arterial partial pressure and $\mathrm{F}_{\mathrm{ET}}\left(\mathrm{CO}_{2}\right)$ is the fractional concentration of end tidal carbon dioxide, $P_{b}$ is barometric pressure ( $\mathrm{mm} \mathrm{Hg}$ ), 47 is the partial pressure of water vapour, and 7.5 the conversion from $\mathrm{mm} \mathrm{Hg}$ to $\mathrm{kPa}$. Dead space as a fraction of tidal volume was derived from the alveolar ventilation equation:

$\dot{\mathrm{V}} \mathrm{E}=\dot{\mathrm{V}} \mathrm{CO}_{2} \times 863 / \mathrm{PaCO}_{2} \times(1-\mathrm{VD} / \mathrm{VT})$

where VD/VT describes dead space ventilation as a proportion of tidal ventilation, $\mathrm{PaCO}_{2}$ is the arterial partial pressure of carbon dioxide, and 863 is a constant to standardise gas measurements to body temperature, pressure and saturation. End tidal carbon dioxide tension was assumed to equate with arterial carbon dioxide tension. ${ }^{10}$

\section{RIGHT VENTRICULAR FUNCTION}

Right ventricular physiology was investigated with transthoracic echocardiography (HewlettPackard Sonus 1500). Pulsed wave Doppler at the midpoint of the main pulmonary artery was used to determine pulmonary arterial systolic and diastolic flow characteristics. The duration of pulmonary regurgitation was also recorded. Patients were defined as having restrictive right ventricular physiology if diastolic pulmonary anterograde flow coinciding with atrial systole was detected. ${ }^{13}$ The duration, velocity and integral of the pulmonary arterial " $a$ " wave were recorded (where present).

using a Bruce protocol modified by the addition of a "stage 0 "-that is, 3 minutes at 1 mile per hour with a $5 \%$ gradient. Patients breathed room air through a one way valve connected to a respiratory mass spectrometer (Innovision, Odense, Denmark). Ventilation (VE), carbon dioxide production $\left(\mathrm{VCO}_{2}\right)$, and oxygen consumption $\left(\mathrm{VO}_{2}\right)$ were calculated on line every ten seconds by an inert gas dilution technique. ${ }^{1112}$

Once ventilation had become stable at rest for at least 2 minutes, patients were encouraged to exercise to exhaustion. At the end of exercise, patients were asked in a standard manner why they had stopped exercising. If they did not answer immediately, the questioner offered breathlessness and fatigue as choices. Blood pressure was measured by sphygmomanometry, with the pressures during exercise being measured during expiration. Heart rate was measured from the electrocardiogram. The respiratory rate was

\section{Results}

The control subjects were well matched for age, body surface area, and predicted peak $\dot{\mathrm{VO}}_{2}$. Although there was no difference between the two groups in absolute values for pulmonary function tests, the normal subjects had a higher mean (SD) percentage predicted $\mathrm{FEV}_{1}(111.4(14.9) \%$ v 97.7 (15.5)\%, $\mathrm{P}=$ $0.03)$ and higher percentage predicted FVC $(115 \cdot 1(16 \cdot 1) \% v 102.9(18.5) \%, P=0.03)$ (table 1). In the Fallot group, 17 had restrictive right ventricular physiology with an inspiratory "a" wave velocity in the pulmonary artery of $31.2(13.6) \mathrm{cm} . \mathrm{s}^{-1}$ and duration of $176.8(36 \cdot 1) \mathrm{ms}$. The pulmonary flow integral was $3.4(1 \cdot 8) \mathrm{cm}$. Twenty subjects had measurable pulmonary regurgitation of 387 $(112.7) \mathrm{s}$ in duration in inspiration and 404 
Table 1 A comparison of variables (mean (SD)) in patents after repair of tetralogy of Fallot and age matched controls

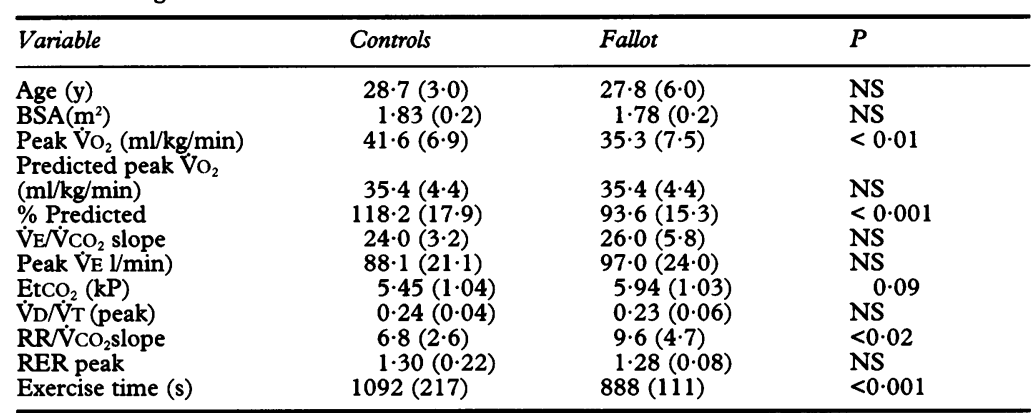

BSA, body surface area; $\dot{\mathrm{VO}}_{2}$, oxygen consumption; $\dot{\mathrm{VE}} / \mathrm{V} \mathrm{CO}_{2}$ slope, slope of the relation between ventilation and carbon dioxide production; $\mathrm{RR} / \mathrm{VCO}_{2}$ slope, slope of the relation between respiratory rate and carbon dioxide production; $\mathrm{EtCO}_{2}$, end tidal carbon dioxide tension; VD/VT, dead space as a fraction of tidal volume; RER, respiratory exchange ratio. Peak refers to peak exercise

Table 2 Division of the patients with repair of tetralogy of Fallot on the basis of their exercise capacity as assessed by percentage of predicted peak $\dot{V}_{2}$ achieved

\begin{tabular}{|c|c|c|c|}
\hline & $\begin{array}{l}\text { Lowest \% achieved } \\
(n=15)\end{array}$ & $\begin{array}{l}\text { Highest } \% \text { achieved } \\
(n=15)\end{array}$ & $P$ \\
\hline 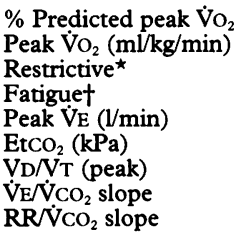 & $\begin{array}{l}81 \cdot 2(8 \cdot 7) \\
31 \cdot 2(5 \cdot 4) \\
6 \\
14 \\
81 \cdot 3(19 \cdot 1) \\
5 \cdot 23(0 \cdot 88) \\
0 \cdot 25(0 \cdot 04) \\
28 \cdot 0(5 \cdot 9) \\
11 \cdot 5(4 \cdot 7)\end{array}$ & $\begin{array}{l}105 \cdot 9(9 \cdot 12) \\
39 \cdot 4(7 \cdot 1) \\
12 \\
7 \\
94 \cdot 5(21 \cdot 5) \\
5 \cdot 66(1 \cdot 16) \\
0 \cdot 23(0 \cdot 04) \\
24 \cdot 1(5 \cdot 1) \\
7 \cdot 8(4 \cdot 0)\end{array}$ & $\begin{array}{l}<0.001 \\
0.001 \\
<0.05 \\
<0.01 \\
\text { NS } \\
0.09 \\
\text { NS } \\
0.06 \\
0.03\end{array}$ \\
\hline
\end{tabular}

^Number of patients in each of the two groups with restrictive right ventricular physiology. $\dagger$ Number of patients in whom exercise was stopped by fatigue.

$(112 \cdot 0) \mathrm{s}$ in expiration. The mean cardiothoracic ratio in the Fallot group was $0.53(0.04)$.

\section{EXERCISE}

There were no adverse effects from any of the exercise tests. All subjects were able to exercise to a point where the respiratory exchange ratio, $\mathrm{RER},\left(\mathrm{V}_{\mathrm{CO}} / \dot{\mathrm{V}}_{2}\right)$ exceeded $1 \cdot 0$, indicating at least near maximal exercise. ${ }^{14}$ In the Fallot group, the average peak oxygen con-

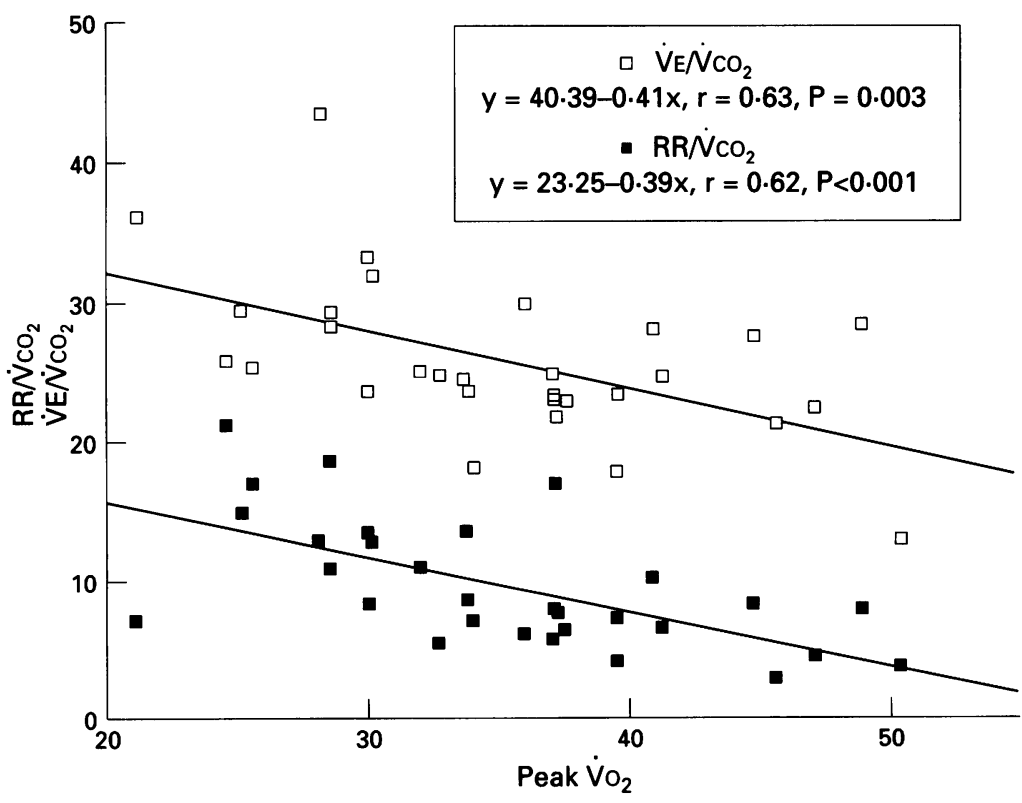

Figure 2 Relations between ventilatory responses to exercise and peak oxygen consumption $\left(\mathrm{VO}_{2}\right)$ in patients with tetralogy of Fallot. $V E / V \mathrm{CO}_{2}$ and $\mathrm{RR} / \mathrm{V} \mathrm{CO}_{2}$ refer to the slopes of the relations between minute ventilation and respiratory rate to carbon dioxide production calculated for each patient as in figure 1. sumption achieved was $35.3(7 \cdot 5) \mathrm{ml} / \mathrm{kg} / \mathrm{min}$, representing $93.6 \quad(15.3) \%$ of the agepredicted maximum. These results were less than for the control group. Exercise time, similarly, was less in the Fallot group of patients $(P<0.001)$. Ventilation at peak exercise was not significantly different in the Fallot group and the controls (table 1 ). The $\mathrm{RR} / \dot{\mathrm{V}} \mathrm{CO}_{2}$ slope was greater in the Fallot group than in controls. In the control group $59 \cdot 1 \%$ were stopped by breathlessness, but only $28.1 \%$ in the Fallot group $\left(\chi^{2}=3.978, P<0.05\right)$.

When the Fallot group was broken into two groups on the basis of their right ventricular physiology on echocardiography, there were no differences between the two groups in age or body surface area. There was no relation between surgical use of a patch and right ventricular physiology. The peak achieved $\dot{\mathrm{VO}}_{2}$ was slightly lower in the non-restrictive group (32.3 (5.8) $\mathrm{ml} / \mathrm{kg} / \mathrm{min} v 37.3(8.0), \mathrm{P}=0.07)$, as was the percentage of predicted peak $\mathrm{VO}_{2}$ $\begin{array}{llllll}\text { achieved } & (82.5 & (10.1) \% & v & 100.9 & (13.8) \text {, }\end{array}$ $\mathbf{P}<0.001)$. The respiratory response to exercise was the same in both groups as assessed by $\dot{\mathrm{V}} / \mathrm{VCO}_{2}$ and $\mathrm{RR} / \dot{\mathrm{V}} \mathrm{CO}_{2}$ slopes.

When patients were divided according to their percentage of peak predicted $\dot{\mathrm{VO}}_{2}$ achieved, those with the lowest exercise capacity were more likely to have non-restrictive right ventricular physiology and to have a greater ventilatory response to exercise (table 2). Patients with lower exercise capacity were more likely to be stopped by a sensation of fatigue than by shortness of breath despite having a greater ventilatory response to exercise.

There was no difference between the group of patients with no measurable pulmonary regurgitation (that is, very mild pulmonary regurgitation) $(n=8)$ and the rest of the patients in either peak $\dot{\mathrm{VO}}_{2}$ or ventilatory response to exercise.

CORRELATES OF EXERCISE PERFORMANCE

There were significant negative correlations between $\mathrm{RR} / \mathrm{VCO}_{2}$ slope and peak $\dot{\mathrm{VO}}_{2}$, and between $\dot{\mathrm{VE}} / \dot{\mathrm{V}} \mathrm{CO}_{2}$ slope and peak $\dot{\mathrm{VO}}_{2}$ (fig 2 ). These correlations were only seen in the Fallot group, and not the controls. Within the Fallot group, there were correlations between peak $\dot{\mathrm{VO}}_{2}$ and both $\mathrm{FEV}_{1}(r=0.39 ; \mathrm{P}=0.04)$ and FVC $(r=0.52 ; \mathrm{P}=0.005)$. There were significant negative correlations between $\mathrm{RR} / \mathrm{VCO}_{2}$ slope and both $\mathrm{FEV}_{1}(r=-0.38 ; \mathrm{P}$ $=0.04)$ and FVC $(r=-0.52 ; \mathrm{P}=0.005)$, but not between pulmonary function tests and $\dot{\mathrm{VE}} / \dot{\mathrm{V}} \mathrm{CO}_{2}$ slope. When pulmonary function tests were expressed as percentages of expected values, the correlations disappeared. There were no correlations between either exercise capacity or ventilatory response and duration of pulmonary regurgitation or pulmonary diastolic flow variables.

There was no correlation between cardiothoracic ratio or cardiac diameter and either exercise performance or ventilatory response to exercise. As would be expected, there is a close correlation between peak ventilation and peak $\dot{\mathrm{V}}_{2}$. Peak ventilation did not correlate with the $\dot{\mathrm{VE}} / \mathrm{VCO}_{2}$ slope $(r=0.04, \mathrm{P}=0.83)$ 
but did correlate closely with $\mathrm{RR} / \dot{\mathrm{V}} \mathrm{CO}_{2}$ slope $(r=0.61 ; \mathrm{P}<0.001)$ and end tidal carbon dioxide $(r=0.71, \mathrm{P}<0.001)$. There was a negative correlation between $\mathrm{VD} / \mathrm{VT}$ at peak exercise and peak $\dot{\mathrm{VO}}_{2}(r=-0.51$, $\mathrm{P}=0.005$ ).

In the controls there were no correlations between exercise capacity and $\mathrm{RR} / \mathrm{VCO}_{2}$ slope, $\dot{\mathrm{VE}} / \mathrm{VCO}_{2}$ slope, or pulmonary function tests and no relation between peak $\mathrm{VD} / \mathrm{VT}$ and peak $\dot{\mathrm{VO}}_{2}$ was seen.

\section{Discussion}

In patients with chronic heart failure, reduced exercise capacity correlates closely with an increase in the ventilatory response to exercise despite the lack of relation with indices of central haemodynamic function. ${ }^{15}{ }^{16}$ It has been suggested that right ventricular function is a more important determinant than left in determining exercise capacity in chronic heart failure. ${ }^{17}$ Against this hypothesis, we have previously shown that in patients 2 to 19 years following Fontan's procedure, many patients exhibit normal exercise capacity and ventilatory responses to exercise despite the absence of a functioning right ventricle. ${ }^{10}$ However, we saw a relation between exercise performance and ventilatory response in the Fallot patients but not the controls.

Previous studies of exercise performance after intracardiac repair of tetralogy of Fallot have reported the absolute ventilation at peak exercise. ${ }^{1819}$ This does not allow a comparison of the ventilatory response to exercise. Peak ventilation necessarily correlates with peak $\mathrm{VO}_{2}$ because the longer incremental exercise continues the greater the rises in $\dot{V}_{2}$ and $\dot{V} E$. Any reduction in peak $\dot{\mathrm{VO}}_{2}$ will coincide with a reduction in peak $\dot{\mathrm{V} E}$. We have selected the $\mathrm{RR} / \dot{\mathrm{V}} \mathrm{CO}_{2}$ and $\dot{\mathrm{VE}} / \dot{\mathrm{V}} \mathrm{CO}_{2}$ slopes as a way of monitoring the ventilatory response during exercise. We have examined the ventilatory responses to exercise of a group of adults with tetralogy of Fallot some 22 years after corrective surgery. We cannot be certain that this group is representative of patients with repaired tetralogy of Fallot because we were unable to study all 80 patients operated on within the study period. In patients in the Fallot group long-term outcome was good, with near normal exercise capacity in most. However, some of the patients had a modest reduction in exercise tolerance, and these were more likely to have non-restrictive right ventricular physiology. The ventilatory response to exercise increased as exercise capacity was reduced, the strongest relation being between the respiratory rate response and peak $\dot{\mathrm{VO}}_{2}$.

The increase in ventilatory response is due mainly to an increase in respiratory rate relative to carbon dioxide production and is seen in those patients with less favourable pulmonary haemodynamics. It is not clear why this relation exists. It is noticeable that the more limited the peak $\dot{\mathrm{Vo}}_{2}$ and the greater the ventilatory response the greater is the peak fractional dead space. The excess dead space may be due to cardiac enlargement resulting in decreased available intrathoracic space for gas exchange. This explanation, however, does not accord with the lack of correlation between cardiac size and ventilatory response. In addition the $V D / V T$ is a variable that is derived from the $\dot{\mathrm{VE}} / \dot{\mathrm{V}} \mathrm{CO}_{2}$ slope (equation 2 ). It may not be appropriate to calculate dead space in this way during incremental exercise, even where the stages are three minutes in length..$^{20}$ It has been suggested that patients with congenital pulmonary artery stenosis have relatively underdeveloped alveoli. ${ }^{21}$ However, this would be expected to decrease measured dead space, unless the pulmonary vasculature was reduced to a greater degree than the alveoli.

It is tempting to speculate that exercise capacity is related to effective pulmonary blood flow. The importance of the respiratory cycle as an additional haemodynamic pump increases as effective pulmonary flow caused by right ventricular contraction decreases: the $\mathrm{RR} / \mathrm{VCO}_{2}$ slope increases as a consequence. This hypothesis fits with the observation of an increase in ventilatory response to exercise in those patients who had undergone the Fontan procedure and who had decreased exercise capacity. ${ }^{1022}$ Despite this increased ventilatory response, fewer of the Fallot patients than controls stopped because of shortness of breath. This finding suggests that the patients may have become adapted to the increased ventilatory response, and are not aware of symptoms of it.

We did not show a close relation between exercise capacity and pulmonary regurgitation, as has previously been reported in children, ${ }^{23}$ but our Doppler methods did not allow a volumetric analysis of pulmonary regurgitation in these patients. Nevertheless, this is the first study to report on the ventilatory responses to exercise of patients with previous repair of tetralogy of Fallot, and to report an increase in respiratory rate relative to carbon dioxide production in the more limited patients. In patients with repair of tetralogy of Fallot the ventilatory pump may be making an important contribution to effective pulmonary blood flow.

1 Murphy JG, Gersh BJ, Mair DD, et al. Long-term outcome in patients undergoing surgical repair of tetralogy of Fallot. N Engl f Med 1993;329:593-9.

2 Borrow KM, Green LH, Castadena AR, Keane JF. Lef ventricular function after repair of tetralogy of Fallot and its relationship to age at surgery. Circulation 1980 61:1150-8.

3 Graham TP, Cordell D, Atwood GF, et al. Right ventricular volume characteristics before and after palliative and reparative operation in tetralogy of Fallot. Circulation reparative operation

4 Redington AN, Oldershaw PJ, Shinebourne EA, Rigby ML. A new technique for the assessment of pulmonary $\mathrm{ML}$. A new technique for the assessment of pulmonary
regurgitation and its application to the assessment of regurgitation and its application to the assessment of
right ventricular function before after repair of tetralogy of right ventricular function before after

5 Carvalho JS, Shinebourne EA, Busst C, Rigby ML, Redington AN. Exercise capacity after complete repair of tetralogy of Fallot: deleterious effects of residual pulmonary regurgitation. Br Heart $\mathcal{f}$ 1992;67:470-3.

6 Cullen S, Shore DF, Redington AN. Characterisation of right ventricular diastolic performance after complete repair of tetralogy of Fallot: restrictive physiology predicts slow postoperative recovery. Circulation 1995;91 1782-9. 
7 Gatzoulis MA, Cullen S, Newman CGH, Redington AN. Diastolic properties of the right ventricle $15-34$ years after repair of tetralogy of Fallot [abstr]. Br Heart $\mathcal{f}$ 1994;71 (May suppl):9.

8 Buller NP, Poole-Wilson PA. Mechanism of the increased ventilatory response to exercise in patients with chronic heart failure. Br Heart $\mathcal{F}$ 1990;63:281-3.

9 Davies SW, Emery TM, Watling MIL, Wannamethee G, Lipkin DP. A critical threshold of exercise capacity in the ventilatory response to exercise in heart failure. $\mathrm{Br}$ Heart $\mathcal{f} 1991 ; 65: 179-83$.

10 Clark AL, Swan JW, Laney R, Connelly M, Somerville J, Coats AJS. The role of right and left ventricular function in the ventilatory response to exercise in chronic heart failure. Circulation 1994;89:2062-9.

11 Davies N, Denison DM. Measurement of metabolic gas exchange and minute volume by mass spectrometry exchange and minute volume by

12 Lipkin DP, Perrins J, Poole-Wilson PA. Respiratory gas exchange in the assessment of patients with impaired exchange in the assessment of patients with i
ventricular function. Br Heart $\mathcal{1} 1985 ; 54: 321-8$.

13 Redington AN, Penny D, Rigby ML, Hayes A. Antegrade diastolic pulmonary arterial flow as a marker of right ventricular restriction after complete repair of pulmonary atresia with intact septum and critical pulmonary stenosis. Cardiol Young 1992;21:382-6.

14 Clark AL, Poole-Wilson PA, Coats AJS. Effects of motivation of the patient on indices of exercise capacity in chronic heart failure. Br Heart $\mathcal{F}$ 1994;71:162-5.

15 Franciosa JA, Park M, Levine TB. Lack of correlation between exercise capacity and indexes of resting left ventricular performance in heart failure. $\mathrm{Am} \mathcal{F}$ Cardiol 1981;47:33-9.

16 Fink LI, Wilson JR, Ferraro N. Exercise ventilation and pulmonary artery wedge pressure in chronic stable congestive heart failure. Am $\mathcal{f}$ Cardiol 1986;57:249-53.

17 Baker BJ, Wilen MM, Boyd CM, Dinh HA, Franciosa JA Relation of right ventricular ejection fraction to exercise capacity in chronic left ventricular failure. $\mathrm{Am} \mathcal{F}$ Cardio 1984;54:596-9.

18 Wessel HU, Cunningham WJ, Paul MH, Bastanier CK, Muster AJ, Idriss FS. Exercise performance in tetralogy of Fallot after intracardiac repair. $\mathcal{F}$ Thorac Cardiovasc Surg 1980;80:582-93.

19 Norgård G, Bjørkhaug A, Vik-Mo H. Effects of impaired lung function and pulmonary regurgitation on maximal exercise capacity in patients with repaired tetralogy of exercise capacity in patients with repa
Fallot. Eur Heart $\mathcal{7} 1992 ; 13: 1380-6$.

20 Clark AL, Volterrani M, Piepoli M, Poole-Wilson PA Coats AJS. The influence of stage duration during incremental treadmill exercise on metabolic gas exchange measurements. Eur Heart f 1993;14(suppl):417.

21 De Troyer A, Yernault J-C, Englert M. Lung hypoplasia in congenital pulmonary valve stenosis. Circulation 1977;56:647-51.

22 Rosenthal M, Deanfield J, Bush A, Redington A. The AP or the TCPC Fontan: which is better? [abstr] $f \mathrm{Am}$ Coll Cardiol 1994;23:191A.

23 Rowe SA, Zahka KG, Manolio TA, Horneffer PJ, Kidd L. Lung function and pulmonary regurgitation limit exercise capacity in postoperative tetralogy of Fallot. $\mathcal{f} \mathrm{Am}$ Coll Cardiol 1991;17:461-6. 